\title{
OXYGEN CONSUMPTION IN THE FATHEAD MINNOW (PIMEPHALES PROMELAS RAFINESQUE)-I.
}

\section{EFFECTS OF WEIGHT, TEMPERATURE, GROUP SIZE, OXYGEN LEVEL AND OPERCULAR MOVEMENT RATE AS A FUNCTION OF TEMPERATURE ${ }^{1}$}

\author{
WILliam D. Wares II and RoXanNe IGRam \\ Department of Biology, The University of Michigan-Flint, Flint, MI 48503, U.S.A.
}

(Received 1 March 1978)

\begin{abstract}
A relationship is evident between oxygen consumption ( $O C$ in $\mathrm{cm}^{3} / \mathrm{hr}$ ) and weight (WT in g) such that:

$$
\mathrm{OC}=-0.580(\mathrm{WT})^{1.053} \text {. }
$$

2. Fathead minnows failed to exhibit immediate rate compensation as a result of acute temperature changes. Minnows showed an exponential increase in weight-specific oxygen consumption with tempera-
\end{abstract} ture (in ${ }^{\circ} \mathrm{C}$ ), resulting in a $\mathrm{Q}_{10}$ of over three. The equation is:

$$
\text { OC }=10^{0.0482} \text { (Temp.) }-1.268 \text {. }
$$

3. Minnows acclimated to water temperatures of $5-21^{\circ} \mathrm{C}$ showed a steady increase in opercular movement rates (OMR) (ventilation rates) as expressed by the equation:

$$
\text { OMR }=0.1968(\text { Temp. })^{2}+1.064 .
$$

4. Grouping more than two fish per chamber resulted in an increase in oxygen consumption. The relationship of group size (GS) to oxygen consumption is:

$$
\mathrm{OC}=0.04059(\mathrm{GS})^{2}-0.2017(\mathrm{GS})+0.5353
$$

5. Oxygen consumption is a function of dissolved oxygen level. This relationship is shown by the equation:

$$
\mathrm{OC}=0.003049(\mathrm{OL})^{3}-0.06359(\mathrm{OL})^{2}+0.4211(\mathrm{OL})-0.4020
$$

where $\mathrm{OL}$ is oxygen level. Due to high variability, it is statistically impossible to determine oxygen level ranges in which they conformed and those in which they regulated.

\section{INTRODUCTION}

Many factors exhibit a marked effect on metabolic rates. Some of these include: ambient temperature, time of day, season, sex, age, level of activity, weight, light level, etc. Also, oxygen consumption of aquatic vertebrates may depend upon ambient $\mathrm{pH}$, osmotic pressure, existing dissolved oxygen levels, group size, etc. This is the first in a series of papers dealing with effects and relationships of most of the above parameters to the bioenergetics of the minnow, Pimephales promelas.

Oxygen consumption has long been considered a valid measure of metabolism. It is also generally accepted that concentrations of dissolved oxygen affect the metabolic rates of aquatic animals (Kusins \& Mangum, 1971).

Most energetics studies consist of only one or two variables. This is unfortunate when one considers that metabolism is a function of several simultaneous internal and external parameters. The purpose of this and subsequent studies is to account for as many of

* Reprint requests should be addressed to: Dr. E. H. Studier, Department of Biology, The University of Michigan-Flint, Flint, MI 48503, U.S.A. these conditions as possible, in order to get a more complete picture of the organism's metabolism.

\section{MATERIALS AND METHODS}

Minnows (Pimephales promelas Rafinesque) used in this study were obtained commercially from the stock of a local bait shop, during March and April, 1977. They were maintained in aerated 30 gallon aquaria at room temperature $\left(21^{\circ} \mathrm{C} \pm 1^{\circ} \mathrm{C}\right)$, and were fed commercial fish food at regular intervals. After acclimation to these laboratory conditions for at least 1 week prior to testing, minnows were exposed to a cycle of $12 \mathrm{hr}$ light and $12 \mathrm{hr}$ dark (centered on 7:00 a.m.) at an average light intensity of $1.5 \mathrm{~W} / \mathrm{m}^{2}$, measured at the experiment vessel surface. All testing was conducted between the hours of 1.00 and 5.00 p.m. in order to avoid variation due to diurnal fluctuations. Essentially all of the water was obtained along with the fish from the bait shop, and used in the studies.

The amount of oxygen consumed was determined at the end of $2 \mathrm{hr}$ runs by the Winkler method, as outlined by Hoar \& Hickman (1967), using a Gilmont $2.0 \mathrm{ml} \mathrm{mi-}$ crometer buret (Roger Gilmont Industries, Inc., Great Neck, NY). In each study the parameters monitored were: $\mathrm{pH}$, osmotic pressure, light level, weight, group size, original dissolved oxygen level, and temperature. This was done in order to make allowances for differences due to 
factors other than the variable being tested, and to protide information for at later multiple regression analysis. All experiments in this study were conducted at an average light intensily of $1.5 \mathrm{~W} \mathrm{~m}^{2}$. Weights were determined by difference using a Mettler model P1200 top loading scale. $\mathrm{pH}$ Was determined with a Fisher model 420 digital pHton meler. Surface light levels were ascentained using a YSI. Kelterine model $65 \mathrm{~A}$ radiometer light moter. Temperature ratings were taken from a slandare (clsius thermometer. Osmotic pressure was measured with an Advanced Instruments Osmometer model 3W. using $0.2 \mathrm{ml}$ samples of water. In each study. controls were run under identical cond tions to determine natural oxygen wse or increase due lo microscopic organisms. Experiment vessels used werc Maron yuart jars of known solume. These transparent jars were arranged so as to isolate the fish from visual stimuli otriside the vessel. which might have influenced activity. Regrescion analyses were performed an a Dual IBM 360.67 system. Statistical significance wats defined as $P: 0.05$. The paragraphs following serve to explain in further detail the conditions of each specilic lest.

Highth

Minnows ranging in waight from 0.47 to $2.23 \mathrm{~g}$ warc usicd.

\section{Timporature}

Six fish were used at each of six different temperatures. chosen in 5 increments from $21027 \mathrm{C}$. All of the minnows had heen previously acdimated $1021 \mathrm{C}$ and had not been led for at least $12 \mathrm{hr}$ prior to experimentation). Jars were preadiusted to the desired experimental temperature.

\section{Group size}

Six jars were filled with aerated aquarium water. Groups of 15 fish were then sealed within these jars. It was known that one fish would have sufficient oxygen to survive a 2 ht period but the limited oxygen supply would not susw tain a harger group for the $2 \mathrm{hr}$ run. Consequently, the amount of time spent in the jar was reduced with increasing group sizc. so that fish-hr remained constant at two (thus. two fish spent $1 \mathrm{hr}$, three fish remained $40 \mathrm{~min}$. etc.).

\section{Oxiden lew}

Before the effects of oxygen level were tested, a standardiation curve was constructed by bubbling oxygen and nitrogen through each of two separate 5 gallon containers. Oxygen content was calculated for samples taken every 30 min from each container. In the actual run, minnows were not acclimated to the new oxygen levels. but were introduced into jars filled with water that bad been aerated with nitrogen or oxygen for varying time spans.

\section{Operentar momement rate}

Minnows were maintained in an aerated aquarium inside a water bath. Changes in the temperature of the aquarium water were effected by regulating the temperature of the water bath. Temperatures below ambient were accomplished by adding ice to the water bath. The fish were allowed to acclimate to a given temperature for 2 or 3 days. Testing originated at $5 \mathrm{C}$. with additional tests conducted at $10,13,18$ and $21 \mathrm{C}$ temperatures. Twelve fish, ach chosen at random. were sampled at each temperature. Opercular movements were counted and recorded for $1 \mathrm{~min}$.

\section{RESLLTS}

For all additional studies reported in this paper. except those dealing with opercular movements and temperature. oxygen consumption has been weightadjusted. In other words. a corrected weight-specific oxygen consumption has been obtained as a function of the variable being studied.

\section{Weight}

Regression analysis of the data obtained yielded a linear relationship when transformed to log log axes. The relationship between weight and oxygen consumption is illustrated by:

$$
Y^{\prime}=-0.580(x)^{1.1153}
$$

where $Y$ is oxygen consumption in $\mathrm{cm}^{3} / \mathrm{hr}$, and $X$ is weight in grams. This transforms into:

$$
\begin{aligned}
\log O C\left(\mathrm{~cm}^{3} / \mathrm{hr}\right)= & -0.580+1.053(\log W T)(\mathrm{g}) . \\
& ( \pm 0.003)( \pm 0.204)
\end{aligned}
$$

where values in parentheses are standard errors for the intercept and slope. $(F=114.038$. d.f. 1 and 25 , $P<0.001$, and $r^{2}=0.82 .1$

\section{Temperante}

Regression analysis of data resulted in a good curvilinear fit. Logarithmic transformation gave a linear relationship of weight-specific oxygen consumption vs temperature. The equation for this relationship is:

$$
\begin{aligned}
& \log O C=0.0482(\text { Temp. })-1.268 \text {, } \\
& ( \pm 0.051) \quad( \pm 0.071)
\end{aligned}
$$

where $O C$ is oxygen consumption $\left(\mathrm{cm}^{3 /} / \mathrm{g}^{1.053}\right.$ per hr). and Temp. is temperature in $C .(F=381.270$, d.f. 1 and 33, $P<0.001$, and $r^{2}=0.920$.)

\section{Group size}

As can be seen in Fig. 1, a possible optimal group size for fathead minnows was indicated by plotting the reduced data. Calculation of regression analysis gave the following equation:

$$
\begin{aligned}
& \mathrm{OC}=0.04059(\mathrm{GS})^{2}-0.2017(\mathrm{GS})+0.5353 . \\
& ( \pm 0.012) \quad( \pm 0.074) \quad( \pm 0.0996)
\end{aligned}
$$

where $O C$ is again oxygen consumption (see above) and GS is Group Size $(F=10.7$, d.f. 1 and 28 , $P<0.001$, and $r^{2}=0.4515$ ). Figure 1 shows the graph of the regression line. Analysis of OC (SNK test) showed no significant difference as a function of GS. Since the slope of the line contains a minimum, we are able to calculate an optimal group size. Taking the first derivative of the regression line will yield this optimum (Studier $t$ al. 1975) as 2.48 fish/vessel or 1 fish $/ 403 \mathrm{~cm}^{3}$.

\section{Oxygen lewel}

Oxygen consumption decreased with a decrease in existing dissolved oxygen level, and increased as existing levels increased. The regression equation is:

$$
\begin{aligned}
\mathrm{OC}=0.003049(\mathrm{OL})^{3}- & 0.0636(\mathrm{OL})^{2} \\
( \pm 0.002) & ( \pm 0.043) \\
& +0.421(\mathrm{OL})-0.4020 \\
& ( \pm 0.246) \quad( \pm 0.393)
\end{aligned}
$$

where $O C$ is oxygen consumption and $O L$ is oxygen level $\left(\mathrm{cm}^{3} /\right) .(F-4.818$ with $I$ and 28 d.f; $P<0.05$; $r^{2}=0.3664$.) Based upon a graph of the regression equation (Fig. 2), the minnows appear to be conformers below $5 \mathrm{~cm}^{3} / 1$ and regulators above. There are probably other factors that prevent a clear demonstration of a breaking point (see Discussion). 


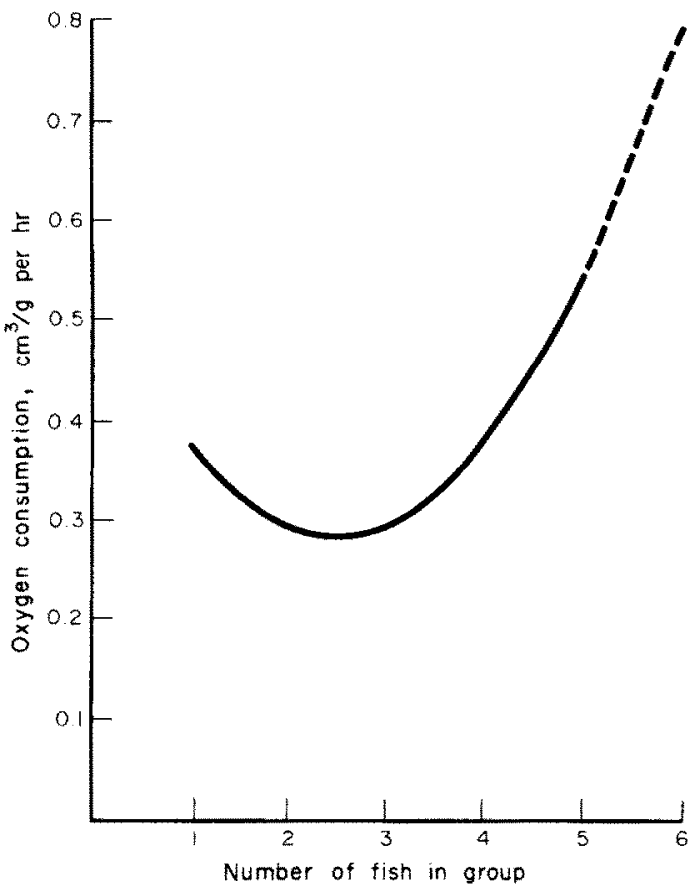

Fig. 1. Oxygen consumption of varying group sizes of fish (Pimephales promelas).

\section{Opercular movement rate}

An extremely strong direct relationship is indicated between opercular movement rates (OMR) and temperature. This is easily seen in Fig. 3. The equation obtained is:

$$
\mathrm{OC}=0.197(\mathrm{OMR})^{2}+1.084
$$

where $O C$ is oxygen consumption $\left(\mathrm{cm}^{3} / \mathrm{g}^{1.053}\right.$ per $\left.\mathrm{hr}\right)$, and $\mathrm{OMR}$ is opercular movement rate (movements/ $\min )$. $(F=588$ with 1 and 58 d.f.; $P<0.001$; $r^{2}=0.910$.)

\section{DISCUSSION}

These studies have attempted to determine metabolic rate of fathead minnows as a function of several parameters. In considering metabolic rate, it should

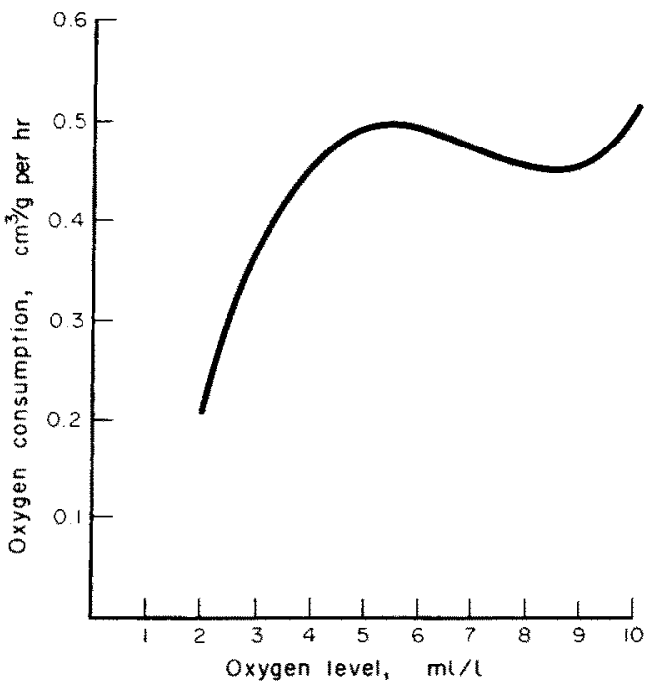

Fig. 2. Oxygen consumption of individual Pimephales promelas at various ambient oxygen levels.

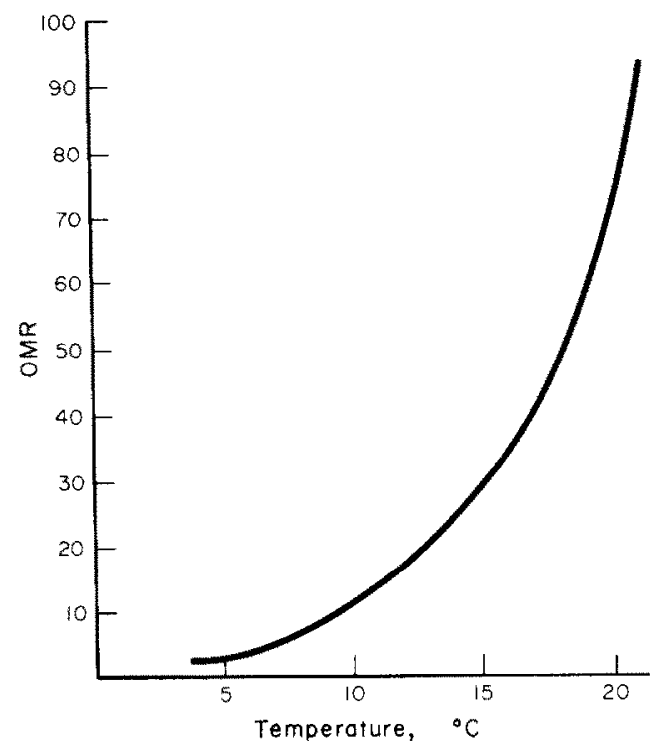

Fig. 3. Opercular movement rates of individual Pimephales promelas at varying ambient temperatures.

be noted that maximal metabolic rate represents a stressful situation, and not an optimal condition. An optimal condition is that which does not require the organism to expend a maximal amount of energy in maintaining its existence.

\section{Weight}

The results indicate the expected linear relationship of oxygen consumption to weight on a $\log -\log$ coordinate system; however, the value of the respiration coefficient is higher than most reported values for fish (Table 1). It is also evident that weight-specific oxygen consumption would increase, rather than decrease, with an increase in weight.

Our data might seem to conflict with all of the values in Table 1 . If one takes into account the confidence limits associated with the value of our respiration coefficient, though it is still at the upper end of the values reported, it is in closer agreement with those results.

It is not unusual to see extremely variable values for the respiration cocfficient, even among related species (Fitch, 1975; Barnes \& Barnes, 1969). It has been suggested by Brody (1945) and Zeuthen (1953) that a value of 0.67 is appropriate for homeotherms. Hemmingsen (1960) found $0.75 \pm 0.015$ (S.E. of slope) was not unusual for poikilotherms. While it can be seen that several of the values listed in Table 1 are in close agreement with Hemmingsen, it will also be noted that several are quite noticeably in conflict with his findings. Prosser \& Brown (1961) make at broad generalization that values may range from 0.67 to 1.0 . The lower value is an expression of the surface area to volume rule which suggests that surface area varies to the $2 / 3$ power of body size. The upper limit of 1.0 would indicate a complete dependence of metabolic rate on body size. Almost all values have been found in this range, or below it, and a value that is less than 1.0 would show weight-specific metabolic rate decreasing with increasing size.

The only exception we were able to find in the literature was documented by Beamish (1964; see 
Table 1. Value of the respiration coefficient

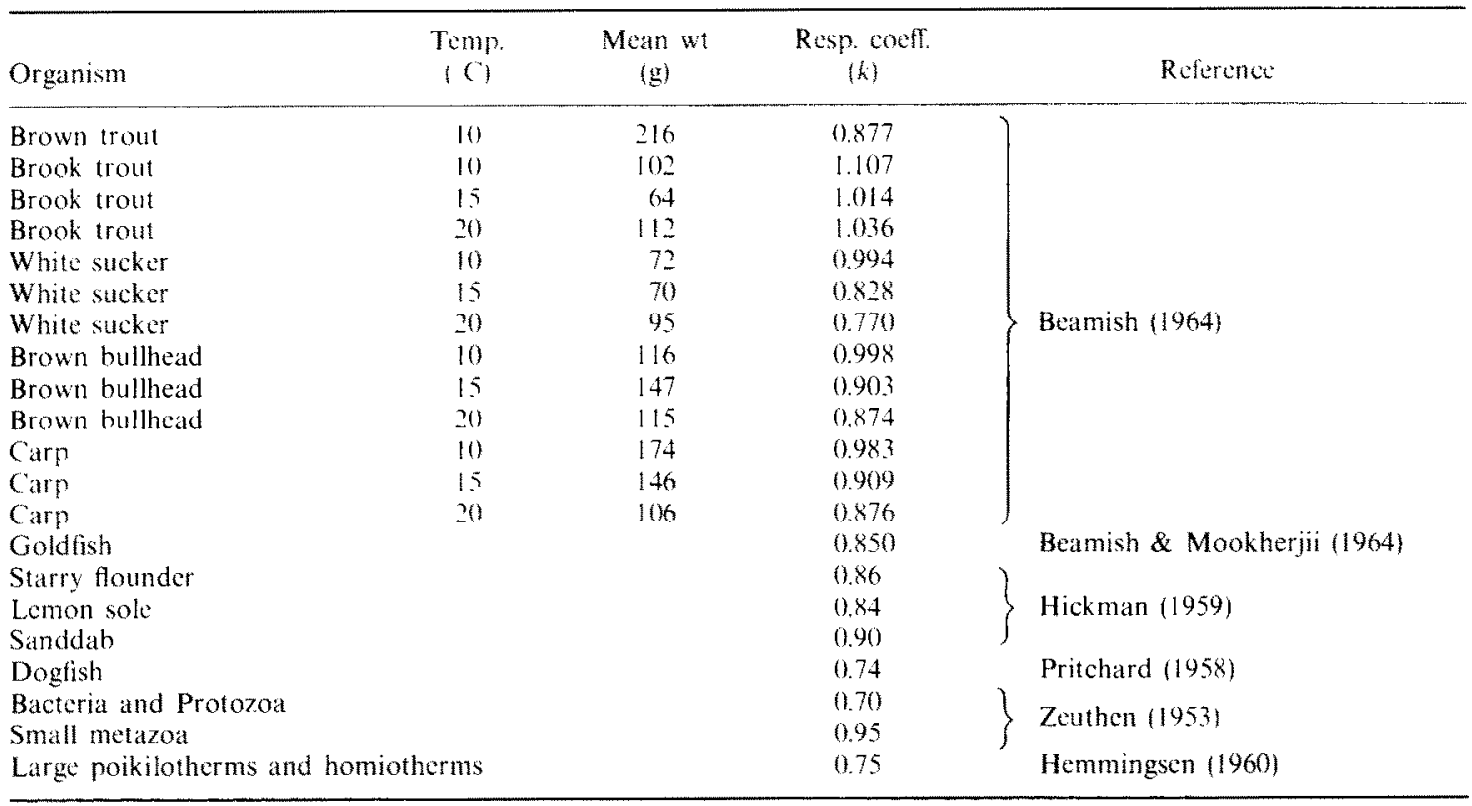

Table 1), and he attributes it to the fact that one of the smaller fishes studied resulted in a respiration coefficient greater than 1.0 , which to him indicated a phylogenetic increase in metabolic rate in smaller animals even though it does not follow ontogenetically. Extrapolation of this argument would suggest that species as small as the fathead minnow would indeed show a larger respiration coefficient. Zeuthen (1953), however, asserted that it must be recognized that values greater than 1.0 are exceptions to the rule. He stated that values greater than 1.0 are only valid for a very narrow weight range. Our study used a weight range large enough that the largest fish weighed nearly five times more than the smallest. This aptly argues Zeuthen"s precept. Since we did not age fish used in our study, ontogenetic differences may be implied. Zeuthen (1953) also contended that respiration coefficients greater than 1.0 could easily result from changes in factors other than size. We attempted to maintain all extraneous environmental conditions fairly constant to alleviate this problem. These factors will be examined in a final multiple regression analysis. One aspect which was not controlled, nor accounted for. was activity. Fox (1936) and Newell (1973) have shown oxygen consumption in relation to body size in intertidal invertebrates and fish to be affected by activity. The possibility of this being true for fathead minnows as well, could explain the discrepancy between this study and those of other authors. Fathead minnows appear to be normally quite active, swimming almost constantly, and due to their small size, their activity levels were not inhibited by the quart jar containers used. Thus, we consider that activity may be an important determinant of the fish's metabolism. A discussion of the effects of activity is planned for a later article.

If it is true that the respiration coefficient is greater than 1.0 because of activity, then we can consider two possible interpretations. We know that the increase is greater for each incremental increase in size and this would imply that the relative activity in- creases with increasing size. Alternatively, a similar level of activity might result in larger weight-specific oxygen demands in the larger fish. We would also consider that with the range offered by our confidence limits, the respiration coefficient might well be 1.0 or slightly below. A larger sample size and more controls on activity will help to make this issue much clearer.

Weymouth et al. (1942), in studies on the kelp crab found $96^{\circ}{ }_{0}$ of the variance in oxygen consumption due to body weight, with only $4^{\circ}$; due to all other factors.

Our study resulted in a large coefficient of determination, indicating a high degree of predictability. Therefore, by use of the equation produced. the effect of weight was eliminated as a variable in the other studies conducted.

\section{Temperature}

Prosser \& Brown (1961) have stated that standard metabolism of fish increases continuously with temperature up to lethal levels, suggesting a rate change of 2.5 times per $10 \mathrm{C}$ in the physiological range. Our study gives a rate change of 3.0 times per $10 \mathrm{C}$. A crude approximation yields a $Q_{1}$ of about three. This is slightly higher than that suggested by Prosser \& Brown (1961). Beamish (1963) stated that freshwater carp have an apparent overall $\mathrm{Q}_{10}$ of about two between 10 and $20 \mathrm{C}$. Brook trout show a similar $Q_{10}$ over this same range (Graham. 1949). Even the saltwater fish used in Merriman's study (1970), Bathygobius ramosus, has an overall temperature coefficient only slightly larger than two. We are able to conclude from this that these minnows appear to exhibit a metabolic rate which is more temperature labile than has been observed in many other species of fish. Though there are some exceptions (see Roberts. 1964). temperature compensation is a rare phenomenon among the species of fish which have been studied. It seems apparent that the enzymes of the fathead minnow are notably resistant to thermal denaturation over a relatively broad temperature range. 
Hochachka \& Somero (1973) believe most biological reactions to occur in a range of $Q_{10}$ values between two and four. Considering this, our $\mathrm{Q}_{10}$ of approximately three does not seem unreasonable, though remarkable.

At $27^{\circ} \mathrm{C}$, the rate of oxygen uptake diminished as oxygen levels of the water decreased. This phenomenon is so general among fish as to be called "respiratory dependence". Several authors (Graham, 1949; Hall, 1930; Maloeuf, 1937) have reported this occurrence for several species of fish. For many fish, respiratory dependence occurs when the oxygen content drops below approximately 5 ppm (Gibson \& Fry, 1953). A more detailed discussion will be found in the section dealing with effects of oxygen level on metabolism.

This study supports the belief that for most fish. and for many ectotherms, weight-specific oxygen consumption increases exponentially with increasing temperature, at least within the critical survival limits of the organism. In particular, fathead minnows exhibit no metabolic compensation over the temperature range studied, and indeed, show a relatively high $\mathrm{Q}_{10}$.

In connection with temperature, an investigation of opercular movement rates (OMR) between 5 and 21 C was conducted. OMRs were found to be temperature labile. We assume minute ventilation volume to be equal to OMR times the volume per movement (considered to be some constant, $k$ ), and, therefore, OMR is directly proportional to minute ventilation volume. We also made the assumption that OMR was related to the partial pressure of oxygen.

It was expected that more opercular movements would be necessitated by the meager amounts of oxygen available in warmer waters. Temperature effects on oxygen solubility influence oxygen uptake adversely by two routes: first, by reducing the diffusion coefficient, and second, by reducing total oxygen content. Both demand an increase in ventilation. Increasing ventilation, however, reduces the thickness of the water film over the surface of the secondary lamellae, which provide the major resistance to gas exchange (Hills \& Hughes, 1970). Increased rate of oxygen uptake during accelerated metabolic activity should be the result of a proportional increased oxygen gradient between the blood and water (Steen \& Kruysse, 1964). Computation of oxygen consumption using the temperature equation, and calculation of OMR using that respective equation, gave a linear relationship when $O C$ (oxygen consumption) was plotted as a function of OMR. Thus, ventilation volume appcars to be connected with temperature and $O C$ can be predicted from OMR.

\section{Group size}

Beyond two fish per jar, the number of fathead minnows contained in a constant volume of water affects the amount of oxygen consumed per gram of fish. These results are contrary to the bulk of previously reported research. Malyukina et al. (1962), Grigor'cva (1966) and Shtefanesku (1958) all reported an inverse relationship of group size to oxygen consumption. Several species were examined, and group effects were found even for those species not given to schooling in the natural habitat. Allee (1931) in summarizing research to that date, assumed group effect to lower oxygen consumption of group members. Schuett (1933) found group effects in gold fish (Carassius auratus), not a noticeably social animal; he was, however, able to obviate the effect by maintaining constant volume per fish with increase in numbers. Bowen (1932) found no significant dissimilarity between grouped and isolated catfish (Ameriurus melas), but felt the results were due to increased activity in the grouped animals.

Here, the fathead minnow, a schooling fish by nature, is found to increase oxygen consumption when surrounded by schoolmates. This would indicate an increased activity on some level. They were not observed to be abnormally active when grouped. Conversely, isolated fish swam more in their vessels than did grouped individuals, intimating an increased demand for oxygen due to some unobserved parameter of metabolism.

Russian scientists (Grigor'eva, 1966; Shtefanesku, 1958) found in some species that olfactory cues are important in determining schooling behavior. Fish were observed to show the same lowered oxygen utilization when isolates were kept in water previously occupied by large numbers of conspecifics. Species exhibiting this effect most markedly were those whose habitat is relatively turbid and stagnant. In this study, while water and fish in all conditions were maintained in separate holding tanks between set-ups, water was not discarded between runs, nor replaced between this and other segments of this experiment. Residual olfactory cues from conspecifics could possibly have accumulated between runs, such that additional fish present in "sweaty" water could have been perceived as over-crowding. Isolated fish would, in this case, be most "uncrowded", and least likely to increase their metabolic rate.

Alternatively, reduction of range of oxygen uptake in response to increased group size could intimate that fathead minnows have an optimal metabolic rate greater than that shown by isolates, and that the presence of conspecifics elevates an individual's rate toward that level. In this event, isolates would have to vellicate much more, to increase their oxygen consumption, and some individuals would be more accomplished than others at this. Aggregates could diminish motor activity, in that stimuli provided by conspecifics trigger a rate increase directed at that level which enables the school to respond appropriately to this environment. The results of this study do not allow the conclusion that fathead minnows have been a schooling species long enough for it to be metabolically more cfficient for the fish to school.

\section{Oxygen level}

Based upon Fig. 3, fathead minnows appear to make a transition between conforming and regulating at a dissolved oxygen level of about $5 \mathrm{~cm}^{3} / 1$. Walshe (1947) subjected species of aquatic insect larvae to low oxygen levels and observed oxygen consumption to decline rapidly, the relationship between oxygen consumption and oxygen level bcing roughly lincar. Walshe dealt with aerated water, as opposed to stagnant water. We assumed fathead minnows to inhabit an environment approximating that of these larvae. We therefore thought our findings would be correlative. Snails not exposed to meager oxygen levels exhi- 
bited partial regulation at higher oxygen levels (Kusins \& Mangum. 1971). These minnows suggested partial regulation at escalated oxygen levels. Our results showed fathead mimows to be neither true conformers nor regulators, but partial regulators and conformers, depending on the oxygen level.

Only information pertaining to partial pressures of carbon dioxide was found for fish, and not direct effects of oxygen levels. Beamish (1964) assumed res. piratory volume of fish in elevated $\mathrm{CO}_{2}$ situations to rise above that of tish in ar-saturated water, consequently raising respiration costs and therefore the rate of oxygen consumption. Beamish (1964), however, demonstrated the standard rate of oxygen consumption to be insignificantly changed in various concentrations of $\mathrm{CO}_{2}$

Walshe (1947) found metabolism in trout directly related to current velocity. This seems plausible when one considers acration as a function of velocity. This could well be related to the motor activity required to maintain position in a current. Activity will be studied as a separate variable in a later work.

Acknowledgenents. We wish to extend our thanks to Dr Eugene H. Studier for his time and supervision of this study. We also thank Dr Richard W. Dapson for his invaluable aid in statistical analysis. We wish to extend our gratitude to Drs Studier. Dapson and Gary L. Pace for their critical evaluation of this manuscript. We thank the Comparative Biology Class of 1977 for their assistance in compiling the data. Data collection for this study was supported by a gant from the Center for Research on Learning and Teaching through the Faculty Development Fund, University of Michigan, Ann Arbor, awarded to Dr Eugene H. Studier.

We thank Mr Ray Shepherd, State of Michigan. Department of Natural Resources. Imlay City for identification of the minnows.

\section{REFERENCES}

ALLEI: W. C. (1931) Animal Agaregation a Study in General Sociology. University of Chicago Press. Chicago.

Barnes H. \& Barnes M. (1969) Seasonal changes in acttely determined oxygen consumption and effect of temperature for three common cirripedes Balanus balonodes (L.), B. halamus (L.) and Chthamalus stellatus (Poli). J. pep. Mar. Biol. 4, 36-50.

Bramish F. W. H. (1963) Respiration of fish with special emphasis on standard oxygen consumption II. Influence of weight and temperature on respiration of several species, Can. J. Zool. 42, 177-188.

Bi:AMISH F. W. H. (1964) Respiration of fishes with special emphasis on standard oxygen consumption. IV. Influence of carbon dioxide and oxygen. Can. $J$. Zool. 42 . 847. 856 .

Bliamish F. W. H. \& Mookhl:kJI P. S. (1964) Respiration of fishes with special emphasis on standard oxygen consumption. I. Influence of weight and temperature on respiration of goldfish. Carassius auratus (L.). Cam. J. Zool. 42, $161-175$

Bowev E. S. (1932) Further studies of the aggregation behavior of Ameiurus melas. Biol. Bull. 63(2), 258-270.

Brony S. (1945) Bioenergetics and Growth, with special Reference to the Efficiency Complex in Domestic Animals. p. 1023, Reinhold, New York.

Firch D. D. (1975) Oxygen consumption in the prosobranch snail Viriparus contectoides (Mollusca: Gastropoda)-1. Effects of weight and activity. Comp. Biochem. Physiol. 51A, $815-820$.

Fox H. M. (1936) The activity and metabolism of poiki- lothermal animals in different latitudes. Pros. zool. Soc. Lend. Part IV. 945955.

Guson M. B. \& FRY F. E. J. $\{1953\}$ Lethal temperature experiments with speckled trout $x$ lake trout hybrids, $I$. Hered. 44(2). 56

Grahay J. M. (1949) Some effects of temperature and oxygen pressure on the metabolism and activity of the speckled trout. Salvelinus fontinalis. Cam. I. Re's. Sect. D. 27, 270288 .

Grigon iva M. B. (1966) Effects of schooling on respiratory metabolism of fishes. Report Summary of the AllUnion Conierence on the Eeology and Physiology of Fishes. Moscow. 130131.

Hat.. F. G. (1930) The ability of the common mackerel and certain other marine fishes to remove dissolved oxygen from sea water tm. J. Phisiol 93, 417421 .

HKKman C. P. (1959) The osmoregulatory role of the thyroid gland in the starry founder Platihhys stellaw. Cum. J. Znol, 37,9971060.

Himmingsin A. M. (1960) Energ? metabolism as related to body size and respiratory surfaces and its evolution. Rép. Stome meml Hosp. 9.7110.

Hul.LS B. A. \& HI CiHlis (S. M. (1970) A dimensional analysis of oxygen transfer in the fish gill. Resp. Physiot. 9. 126140 .

HOAR W. S. \& HICKAN C. P. (1967) a Lahoratory Comparism for Genteral smal Comparate Phisiolagl: p. 286. Prentice-Hatl. Englewood Cliffs.

Hochachka P. W. \& Somiro G. N. (1973) Stralcgies of Biochemical Adaptation 358 pp. Saunders, Philadelphia.

Kisst.s L. I. \& Manit M C. P. (197) Responses to low oxygen conditions in two species of the mud snail Nassarits. Comp. Biochem. Physiol. 39A. 421-435.

MaLor(f N. S. R. (1937) Studies on the respiration of animals I and II. Z. veryl. Physiol. 25, I-4?.

Malyl kina G. A. Alliksanchylk S. P. \& Shtlefaniskl: M. (1962) On the role of the vision in "schooling effect" in minnows. Phloxinus phloxinus L. and goldfish Carassines carassius L. Vopr. Ikhtiol 2(3) 511516.

Mirriman D. (1970) The califaction of a river. Scient. $4 \mathrm{~m}$. 222. 4252.

NiwlLL R. C. (1973) Factors affecting the respiration of intertidal invertebrates. $4 \mathrm{~m} . \mathrm{Zool}$. 13. 513.528.

PriT(Harl) A. W. (1958) Relationship between metabolic rate and body size in an elasmobranch (Squalus sucklevi) and in a teleost (Ophiodon elongatus) J. Mar. Res. Found. 17,403411

Prosstr C. L. Brown F. A. Je (1961) Comparative Animal Physiology, 2nd edition, p. 164. W. B. Saunders, Philadelphia

ROBk:RTS J. L. (1964) Metabolic responses of fresh-water sunfish to seasonal photoperiods and temperatures. $\mathrm{He}$ golländer wiss. Meceresunters 9. 459-473.

ScHel:Tt F. (1933) Studies in mass physiology: the effect of numbers on oxygen consumption of fishes. Ecology 14. $106-122$

SuTIFAnEski: M. (195\%) Physiological analysis of the correlation beiween gas exchange and schooling behavior of some marine and fresh water fish. Zool. Zh. 37(2), $22222 x$.

Stein I. R \& KRiYssi: A. (1964) Respiratory function of fish gills. Comp. Biochem. Physiol. 12, 127-142.

Stlibtir F. H. DAPSON R. W. \& Bigelow R. E. (1975) Analysis of polynomial functions for determining maximum or minimum conditions in biological systems Comp. Biochem. Physiol. 52A, 1920.

WALSHI: B. M. (1947) The oxygen requirements and thermal resistance of chironomid larvae from flowing and from still waters. J. exp. Biol. 25, 35 44 .

Weymouth F. W. Fiflis J. II \& Kleiber M. (1942) Relation between body size and metabolism. Proc. Soc. exp. Biol. Med. 49, 367.

ZiLTHEN E (1953) Oxygen uptake as related to body size in organisms. $Q$. Rél. Biol. 28, $1-12$ 